\title{
Speech outcomes following Sommerlad primary palatoplasty: results of the Ghent University Hospital
}

Laura Bruneel ${ }^{\mathrm{a}, *}$, Kim Bettens ${ }^{\mathrm{a}}$, Marc De Bodt ${ }^{\mathrm{a}, \mathrm{b}, \mathrm{c}}$, Nathalie Roche ${ }^{\mathrm{d}}$, Katrien Bonte $^{\mathrm{e}}$ and Kristiane Van Lierde $\mathrm{e}^{\mathrm{a}, \mathrm{f}}$

${ }^{a}$ Department of Speech, Language and Hearing Sciences, Ghent University, Ghent, Belgium

${ }^{b}$ Faculty of Medicine and Health Sciences, Antwerp University, Antwerp, Belgium

${ }^{c}$ Rehabilitation Centre for Communication Disorders, Antwerp University Hospital, Edegem, Belgium

${ }^{\mathrm{d} D e p a r t m e n t}$ of Plastic and Reconstructive Surgery, Ghent University Hospital, Ghent, Belgium

${ }^{e}$ Department of Head and Neck Surgery, Ghent University Hospital, Ghent, Belgium

${ }^{\mathrm{f}}$ Department of Speech-Language Pathology and Audiology, University Of Pretoria, Pretoria, South Africa

* Corresponding author at: Laura Bruneel, Department of Speech, Language and Hearing Sciences, Corneel Heymanslaan 10, BE-9000 Ghent, Belgium.

E-mail address: Laubrune.bruneel@ugent.be (L. Bruneel). 


\title{
Highlights
}

1. Speech disorders were still present following Sommerlad's palatoplasty.

2. Speech of the patients was significantly worse compared to the control group.

3. A standardized Dutch speech assessment protocol is advocated.

\begin{abstract}
:
Objective and subjects: Speech outcomes were described for 16 patients with cleft palate (mean age: 5.4 years) following Sommerlad primary palatoplasty performed by a single surgeon of the Ghent University Hospital. These speech outcomes were compared with those of an age and gender matched control group without cleft palate (mean age: 5.3 years).
\end{abstract}

Methods: Speech intelligibility/distinctiveness, resonance, nasal airflow and articulation, were perceptually evaluated. Additionally, nasalance values and the NSI 2.0 were determined.

Results: In seven patients, speech intelligibility/distinctiveness was disordered. Hypernasality was present in twelve participants, whereas nasal emission and nasal turbulence were perceived in thirteen and five patients respectively. Both perceptual and instrumental speech evaluations were significantly poorer in the patient group in comparison to the control group. 
Conclusions: Patients still present with both obligatory and compensatory speech disorders following Sommerlad's palatoplasty. In the future, a Dutch speech assessment protocol will be developed in order to standardize follow-up of these patients and to allow for within-center and inter-center comparisons.

\section{Introduction}

Clefts of the (lip and) palate are one of the most common congenital abnormalities, with incidence estimated at 1 in 1000 live births (Dixon, Marazita, Beaty, \& Murray, 2011). The final goal of the multidisciplinary approach of these patients, is the well-functioning of the patient in society (John, Sell, Sweeney, Harding-Bell, \& Williams, 2006), with special attention for speech outcomes, maxillofacial growth and aesthetic outcomes (Leow \& Lo, 2008; Sommerlad, 2002). Primary palatal surgery, is one of the first steps in providing the patient with cleft palate optimal care (Andrades et al., 2008). For the closure of the soft and/or hard palate, several techniques have been developed over the years (Agrawal, 2009; Leow \& Lo, 2008; Moore, Lawrence, Ptak, \& Trier, 1988). The outcome of these techniques is determined by speech results, such as resonance and articulation, and by structural aspects, such as velopharyngeal closure and the presence of postoperative fistulae (Agrawal, 2009). 
At the Ghent University Hospital, the Sommerlad technique (Sommerlad, 2003) is frequently used for primary closure of the cleft palate. The Sommerlad technique has been described as a more physiological approach, aiming to restore the anatomy of the velum (Sommerlad, 2003). This technique, often described as radical intravelar veloplasty, has the following distinctive components: a radical retroposition of velar musculature (m. levator veli palatini, m. palatoglossus and m. palatopharyngeus), combined with a minimal dissection of the hard palate, a tensor tenotomy, and the repair of the $\mathrm{m}$. levator sling (Sommerlad, 2003). Sommerlad (2003) reported positive results following this technique, showing a decrease in velopharyngeal insufficiency and related resonance disorders.

Several subsequent studies have described the outcomes following Sommerlad's radical intravelar veloplasty (table 1). These studies often provided speech outcomes following a specific surgical protocol including radical intravelar veloplasty, illustrating the diversity between centers in the surgical approach of patients with cleft palate. Consequently, the results of the studies listed in table 1 reflect the surgical approach of a specific craniofacial center.

Despite this diversity, all studies reported improved speech following Sommerlad's primary palatoplasty, either concluded based on pre and postoperative measurements (Sommerlad et al., 2004) or by comparing speech results following a surgical approach including Sommerlad's technique with other techniques (e.g. Andrades et al. (2008); Doucet et al. (2013); Dissaux et al. 
Table 1: literature review of speech results following Sommerlad primary palatoplasty

\begin{tabular}{|c|c|c|c|c|c|}
\hline$n$ and cleft type & $\begin{array}{l}\text { Timing of the surgical } \\
\text { technique }\end{array}$ & Speech assessment & $\begin{array}{l}\text { Age at speech } \\
\text { assessment }\end{array}$ & $\begin{array}{l}\text { Control } \\
\text { group }\end{array}$ & Speech results \\
\hline \multicolumn{6}{|c|}{ Sommerlad et al. (2004) } \\
\hline $40 \mathrm{SMCP}$ & $\begin{array}{l}\text { Sommerlad primary } \\
\text { palatoplasty (Sommerlad, } \\
\text { 2003) } \\
\text { Mean age: } 8.2 \text { years (range: } \\
\text { 3-27 years) }\end{array}$ & $\begin{array}{l}\text { Perceptual evaluation of } \\
\text { nasality and nasal emission } \\
\text { (CAPS- Harding et al. } \\
\text { (Harding, Harland, \& } \\
\text { Razzell, 1997)) }\end{array}$ & \begin{tabular}{llr}
\multicolumn{2}{l}{ Postoperative } \\
assessment: & : mean \\
age 8.3 & months \\
(range: 5 & - & 19 \\
months) & & \\
& &
\end{tabular} & No & $\begin{array}{l}\text { Improvement of nasality in } 85 \% ; 33 \% \text { had normal } \\
\text { nasality. Improvement of nasal emission in } 63 \% ; 68 \% \\
\text { had absent, or mild and inconsistent nasal emission. }\end{array}$ \\
\hline \multicolumn{6}{|l|}{ Andrades et al. (2008) } \\
\hline $\begin{array}{l}49 \text { Veau type II } \\
41 \text { Veau type III } \\
13 \text { Veau type IV }\end{array}$ & $\begin{array}{l}\text { Two-flap palatoplasty } \\
\text { (Bardach, 1995; Salyer, Sng, } \\
\& \text { Sperry, 2006)+ radical } \\
\text { intravelar veloplasty } \\
\text { (Sommerlad, 2003) }\end{array}$ & $\begin{array}{l}\text { Perceptual (Sell, Harding, } \\
\& \text { Grunwell, 1999) and } \\
\text { objective evaluation of } \\
\text { resonance (Nasometer) } \\
\text { Assessment of articulation: } \\
\text { Goldman-Fristoe } \\
\text { articulation test } \\
\text { Perceptual assessment of } \\
\text { speech intelligibility (three- } \\
\text { point scale) }\end{array}$ & $\begin{array}{l}\text { Postoperative } \\
\text { assessment : mean age } \\
3.1 \text { years } \pm 0.6\end{array}$ & No & $\begin{array}{l}\text { Significantly less hypernasality after radical veloplasty; } \\
\text { hypernasality was absent in } 33.3 \% \text {. Significantly less } \\
\text { nasal emission; nasal emission was absent in } 46.7 \% \text {. } \\
40 \% \text { of the patients had velopharyngeal sufficiency. } \\
\text { Significantly less articulatory disorders after radical } \\
\text { veloplasty. }\end{array}$ \\
\hline
\end{tabular}




\begin{tabular}{|c|c|c|c|c|c|}
\hline $\begin{array}{l}\text { n and } \\
\text { cleft } \\
\text { type }\end{array}$ & $\begin{array}{l}\text { Timing of the surgical } \\
\text { technique }\end{array}$ & Speech assessment & $\begin{array}{l}\text { Age at speech } \\
\text { assessment }\end{array}$ & $\begin{array}{l}\text { Control } \\
\text { group }\end{array}$ & Speech results \\
\hline \multicolumn{6}{|c|}{ Doucet et al. (2013) } \\
\hline $\begin{array}{l}20 \\
\text { UCLP }\end{array}$ & 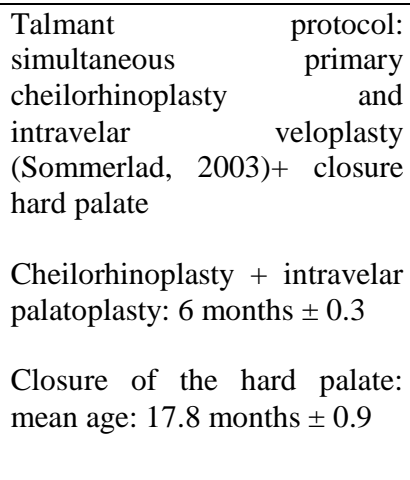 & $\begin{array}{l}\text { Perceptual assessment of resonance and } \\
\text { intelligibility (Henningsson et al., 2008) } \\
\text { Perceptual assessment of articulation } \\
\text { Assessment of velopharyngeal insufficiency: } \\
\text { Borel-Maisonny scale (Borel-Maisonny, 1975) } \\
+ \text { aerophonoscopy (Rineau, 1993) }\end{array}$ & $\begin{array}{l}\text { Postoperative } \\
\text { evaluation: mean age } \\
3.3 \text { years }\end{array}$ & No & $\begin{array}{l}\text { Significantly less nasal emission (objective } \\
\text { evaluation) after the Talmant protocol in } \\
\text { comparison to the Malek protocol (without } \\
\text { intravelar veloplasty). } \\
\text { A delay of } 1 \text { year or more in articulatory } \\
\text { development in } 15 \% \text {. Good speech } \\
\text { intelligibility in } 75 \% \text {. Significant less } \\
\text { velopharyngeal insufficiency when } \\
\text { intravelar palatoplasty was applied; } \\
\text { velofaryngeal insufficiency in } 15 \% \text {. }\end{array}$ \\
\hline \multicolumn{6}{|c|}{ Yang et al. (2013) } \\
\hline $\begin{array}{l}62 \\
\text { BCCP } \\
170 \\
\text { UCCP } \\
\\
256 \\
\text { ICP } \\
\\
15 \\
\text { SMCP }\end{array}$ & $\begin{array}{l}\text { Sommerlad primary } \\
\text { palatoplasty (Sommerlad, } \\
\text { 2003) } \\
\text { Mean age: } 3.7 \text { years (range: } 10 \\
\text { months - } 27 \text { years) }\end{array}$ & $\begin{array}{l}\text { Perceptual assessment of resonance (Rudnick \& } \\
\text { Sie, 2008; Sie \& Chen, 2007) + } \\
\text { videonasofarygnoscopy }(50 \%)\end{array}$ & $\begin{array}{l}\text { Postoperative } \\
\text { evaluation: } 6 \text { months - } 2 \\
\text { years after surgery }\end{array}$ & No & $\begin{array}{l}59.6 \% \text { Velopharyngeal competence } \\
3.78 \% \text { Borderline velopharyngeal } \\
\text { competence }\end{array}$ \\
\hline
\end{tabular}




\begin{tabular}{|c|c|c|c|c|c|}
\hline $\begin{array}{l}\text { n and } \\
\text { cleft type }\end{array}$ & $\begin{array}{l}\text { Timing of the surgical } \\
\text { technique }\end{array}$ & Speech assessment & $\begin{array}{l}\text { Age at speech } \\
\text { assessment }\end{array}$ & $\begin{array}{l}\text { Control } \\
\text { group }\end{array}$ & Speech results \\
\hline \multicolumn{6}{|c|}{ Luyten et al. (2013) } \\
\hline $\begin{array}{l}1 \text { BCLP } \\
10 \mathrm{UCLP}\end{array}$ & $\begin{array}{l}\text { Sommerlad primary } \\
\text { palatoplasty (Sommerlad, } \\
\text { 2003) } \\
\text { Mean age: } 3.4 \text { months (range } \\
\text { 2-6 months) }\end{array}$ & $\begin{array}{l}\text { Perceptual (John et al., 2006) and } \\
\text { objective assessment } \\
\text { (Nasometer) of resonance } \\
\text { Assessment of articulation: } \\
\text { Photo Articulation Test - 3rd } \\
\text { edition (PAT-3) }\end{array}$ & $\begin{array}{l}\text { Postoperative } \\
\text { evaluation: mean age } \\
4.9 \text { years (range } 3.2- \\
7.2 \text { years) }\end{array}$ & $\begin{array}{l}\text { Yes, age and gender } \\
\text { matched ( } 2 \text { for } 1 \\
\text { experimental } \\
\text { subject) } \\
\text { Control group } \\
(\mathrm{n}=22) \text { : mean age } \\
4.1 \text { years } \\
\text { (range: } 3.0-7.1 \\
\text { years) }\end{array}$ & $\begin{array}{l}\text { Cleft palate: } \\
\text { - more omissions, distortions and } \\
\text { substitution in comparison to the control } \\
\text { group } \\
\text { - higher frequency of compensatory } \\
\text { articulation } \\
\text { - in } 100 \% \text { at least one phonological process } \\
\text { was present (and in } 55 \% \text { of the control } \\
\text { group) } \\
\text { - hypernasality was present in } 18 \% \text { of the } \\
\text { patients; nasal emission in } 27 \%\end{array}$ \\
\hline
\end{tabular}




\begin{tabular}{|c|c|c|c|c|c|}
\hline $\begin{array}{l}n \text { and cleft } \\
\text { type }\end{array}$ & $\begin{array}{l}\text { Timing of the surgical } \\
\text { technique }\end{array}$ & Speech assessment & $\begin{array}{l}\text { Age at speech } \\
\text { assessment }\end{array}$ & $\begin{array}{l}\text { Control } \\
\text { group }\end{array}$ & Speech results \\
\hline \multicolumn{6}{|c|}{ Luyten et al. (2014) } \\
\hline $\begin{array}{l}\text { Ugandan } \\
\text { patients (UP): } \\
1 \mathrm{BCLP} \\
10 \mathrm{UCLP} \\
1 \mathrm{CP} \\
\text { Belgian } \\
\text { patients (BP): } \\
1 \mathrm{BCLP} \\
10 \mathrm{UCLP} \\
1 \mathrm{CP}\end{array}$ & $\begin{array}{l}\text { Sommerlad primary } \\
\text { palatoplasty (Sommerlad, } \\
\text { 2003) } \\
\text { Mean age UP: } 3.3 \text { months } \\
\text { (range } 2-6 \text { months) } \\
\text { Mean age BP: } 11.1 \text { months } \\
\text { (range 9-15 months) }\end{array}$ & $\begin{array}{l}\text { Perceptual (John et al., 2006) and } \\
\text { objective assessment (Nasometer) of } \\
\text { resonance } \\
\text { Assessment of articulation: PAT-3 } \\
\text { (UP); picture naming test (Van Borsel, } \\
2003 \text { ) (BP) }\end{array}$ & $\begin{array}{l}\text { Postoperative } \\
\text { evaluation } \\
\text { UP: mean age } 4.9 \text { years } \\
\text { (range } 3.2-7.2 \text { years) } \\
\begin{array}{l}\text { BP: mean age } 4.7 \text { years } \\
\text { (range } 2.6-6.11 \text { years) }\end{array}\end{array}$ & $\begin{array}{l}\text { Yes, age and } \\
\text { gender } \\
\text { matched } \\
\text { Ugandan } \\
\text { control group: } \\
\text { mean age } 4.1 \\
\text { years (range: } \\
3.0-7.1 \\
\text { years) } \\
\text { Belgian } \\
\text { control group: } \\
\text { mean age } 4.6 \\
\text { years (range } \\
2.9-6.10 \\
\text { years) }\end{array}$ & $\begin{array}{l}\text { UP } 89 \% \text { acquired consonants; BP } 81 \% \text {. } \\
\text { UP } 92 \% \text { at least one phonetic error; BP } \\
100 \% \text {. BP significantly more distortions } \\
\text { in comparison to UP. UP } 100 \% \text { at least } \\
\text { one phonological process, BP } 75 \% \text {. } \\
\text { UP } 75 \% \text { no hypernasality and } 75 \% \text { no } \\
\text { nasal emission/turbulence; BP } 50 \% \text { and } \\
67 \% \text { respectively. }\end{array}$ \\
\hline \multicolumn{6}{|c|}{ Dissaux et al. (2016) } \\
\hline $\begin{array}{l}10 \text { UCLP } \\
10 \text { BCLP }\end{array}$ & $\begin{array}{l}\text { Talmant protocol (Talmant, } \\
\text { Talmant, \& Lumineau, 2007; } \\
\text { Talmant, 2000) } \\
\text { 6-8 months: Millard lip } \\
\text { repair and primary } \\
\text { septorhinoplasty (Millard } \\
\text { modified Talmant technique) } \\
+\quad \text { Sommerlad intavelar } \\
\text { palatoplasty (Sommerlad, } \\
\text { 2003) } \\
\text { 12-14 months: hard palate } \\
\text { closure without raising flaps } \\
\text { Mean age: unknown }\end{array}$ & $\begin{array}{l}\text { Assessment of velopharyngeal } \\
\text { insufficiency: Borel-Maisonny scale } \\
\text { (Borel-Maisonny, 1975) + } \\
\text { aerophonoscopy (Rineau, 1993) }\end{array}$ & $\begin{array}{l}\text { Postoperative } \\
\text { evaluation: mean age } \\
5.1 \text { years (range } 4.3- \\
5.8 \text { years) }\end{array}$ & No & $\begin{array}{l}\text { Results of the Borel-Maissony scale: } \\
\text { UCLP: I } 61 \% \text {, IIB } 25 \% \text {, IIM } 7 \% \text {, III } 7 \% \\
\text { BCLP: I } 62.5 \% \text {, IIB } 25 \% \text {, IIM } 10 \% \text {, III } \\
0 \% \\
\begin{array}{l}\text { Better speech results following this } \\
\text { protocol in comparison to } 3 \text { other } \\
\text { protocols without Sommerlad's } \\
\text { palatoplasty }\end{array}\end{array}$ \\
\hline
\end{tabular}




\begin{tabular}{|c|c|c|c|c|c|}
\hline \multicolumn{6}{|c|}{ Nyberg, Neovius, and Lohmander (2017) } \\
\hline $\begin{array}{l}\text { Speech } \\
\text { assessment at } \\
\text { a mean age of } \\
5.2 \text { years: } \\
58 \mathrm{CP} \\
\text { Speech } \\
\text { assessment at } \\
\text { a mean age of } \\
10.3 \text { years: } \\
78 \mathrm{CP}\end{array}$ & $\begin{array}{l}\text { Sommerlad primary } \\
\text { palatoplasty (Sommerlad, } \\
2003 \text { ) } \\
\text { Mean age: } 13.6 \text { months (SD: } \\
4.6 \text { months) }\end{array}$ & $\begin{array}{l}\text { Perceptual assessment of the speech } \\
\text { variables hypernasality, audible nasal } \\
\text { air leakage, weak pressure consonants, } \\
\text { compensatory articulation, s-distortions } \\
\text { (five-point scales) and perceived } \\
\text { velopharyngeal function and general } \\
\text { impression of speech (four-point } \\
\text { scales). }\end{array}$ & $\begin{array}{l}\text { Postoperative } \\
\text { evaluation: at a mean } \\
\text { age of } 5.2 \text { years (range } \\
4.0-6.4 \text { years) and a } \\
\text { mean age of } 10.3 \text { years } \\
\text { (range: } 9.1-11.8 \text { years) }\end{array}$ & No & $\begin{array}{l}\text { Results at } 5 \text { years of age: normal } \\
\text { resonance in } 66 \% \text {, absent nasal air } \\
\text { leakage in } 62 \% \text {, normal pressure } \\
\text { consonants in } 88 \% \text {, absent compensatory } \\
\text { articulation in } 93 \% \% \text {, normal s- } \\
\text { production in } 60 \% \text {, competent } \\
\text { velopharyngeal function in } 88 \% \text {. } \\
\text { Results at } 10 \text { years of age: statistical } \\
\text { improvement of all variables, with the } \\
\text { exception of audible nasal air leakage } \\
\text { (deterioration). }\end{array}$ \\
\hline
\end{tabular}

Abbreviations table 1:

\begin{tabular}{|l|l|}
\hline SMCP & Submucous cleft palate \\
\hline UCLP & Unilateral cleft lip and palate \\
\hline BCCP & Bilateral complete cleft palate \\
\hline UCCP & Unilateral complete cleft palate \\
\hline ICP & Incomplete cleft palate \\
\hline SMCP & Submucous cleft palate \\
\hline BCLP & Bilateral cleft lip and palate \\
\hline UCLP & Unilateral cleft lip and palate \\
\hline CP & Cleft palate \\
& \\
\hline
\end{tabular}


(2016)). On the other hand, some studies only reported descriptive speech results (Yang et al., 2013). Often, speech outcomes were described in terms of prevalence of the parameters hypernasality and nasal airflow, and the competence of the velopharyngeal mechanism. In contrast, no or only limited speech results regarding intelligibility and articulation disorders were reported in most studies, although these parameters are generally acknowledged as important parameters in cleft palate speech assessment (Harding \& Grunwell, 1996; Kummer, 2008; Kummer, 2011). Furthermore, a comparison of speech results of patients with cleft palate following Sommerlad's palatoplasty with those of a control group without cleft palate has been seldom reported, despite the knowledge that one of the primary aims of treatment in patients with cleft palate is to normalize speech (Sommerlad, 2002),

The main purpose of this study was to describe speech outcomes following a primary palatal closure using Sommerlad's technique performed by a single surgeon of the Ghent University Hospital, as to date no such information was available yet. More specifically, the aim was to provide detailed speech results regarding speech intelligibility/distinctiveness, resonance, nasal airflow and articulation. In addition, speech results were compared with those of an age and gender matched control group without cleft lip and/or palate in order to evaluate whether speech can be considered within the normal range. 


\section{Materials and methods:}

This study followed the Declaration of Helsinki on medical protocol and ethics and the regional Ethical Review Board of the Ghent University Hospital (2014/0979). All parents of the participants signed an informed consent document.

\subsection{Participants}

The patients were recruited from the craniofacial team of the Ghent University Hospital and were all born with a non-syndromic isolated cleft (lip and) palate. The patient's case history, including surgical information, was retrieved from their medical records and by interviewing the parents. The patient group consisted of ten girls and six boys with a mean age of 5.4 years (standard deviation $(S D): 1.2$, range: $3.8-8.6$ years). Eight patients had a unilateral cleft lip and palate (UCLP), 4 patients presented with a bilateral cleft lip and palate (BCLP) and four patients with a cleft palate (CP) only. In patients with cleft lip, cheiloplasty with primary nasal correction was performed at a mean age of 3 months ( $S D: 0.9$, range: 2-5 months). For incomplete cleft lip, the technique described by Fisher (Fisher, 2005) was used; for complete cleft lip, a modified Millard rotation advancement procedure was performed (no alar base incision, septal flap for closure of the nasal floor and vomerine flap for closure of the anterior part of the hard palate). For bilateral cleft lip, closure was performed according to Fisher (Fisher, 2005); no vomerine flap procedure was done. Clefts of the palate were repaired using Sommerlad primary palatoplasty (Sommerlad, 2003 ) at a mean age of 12 months ( $S D: 4.5$, range: 7-25 months). Each procedure 
was performed by a single experienced surgeon (lip closure: N.R., palatoplasty: K.B.). Speech assessment was conducted on average 52 months ( $S D: 14.9$, range: 33-93 months) after primary palatoplasty. At the time of the assessment, none of the patients had received a secondary palatoplasty. Eight patients followed speech therapy (mean duration: 23 months). Six patients had one hour of speech therapy per week, one patient had a half hour per week and another patient one and a half hour per week.

An age and gender matched control group of peers without cleft palate was constructed by convenience sampling and were contacted face to face, by e-mail or phone. This group had a mean age of 5.3 years $(S D: 1.1$, range: $3.9-8.5$ years) which did not significantly differ from the age of the patient group $(U=$ $134.00, z=+0.23, p=0.838, r=+0.04)$. Participants of the control group had no history of nasal or laryngeal pathology, and no speech and/or language pathology. All participants of both the patient group and the control group had Dutch as their native language, no cognitive or neuromotor delay, no moderate or severe hearing loss, and were not suffering from a cold or an allergic outburst at the moment of the data collection. Thirteen patients and one participant of the control group received ear ventilation tubes at least once.

\subsection{Perceptual assessment of speech}

For the evaluation of speech intelligibility/distinctiveness, hypernasality, hyponasality, nasal emission, nasal turbulence and nasal grimace, speech samples were collected consisting of spontaneous speech, counting from 1 to 10 , 
reciting the days of the week, and repetition of the Dutch version of the SNAP test (MacKay \& Kummer, 1994; Van Lierde, De Bodt, Van Borsel, Wuyts, \& Van Cauwenberge, 2002). Based on this speech sample, these parameters were evaluated following the scoring guidelines and definitions of the CAPS-A protocol described by John et al. (2006). The parameters of this protocol are constructed specifically for outcome studies, using equal appearing interval (EAI) scaling with clear description of each grade for the above-mentioned parameters. As such, intelligibility/distinctiveness and hypernasality were evaluated using a five-point scale, whereas for the evaluation of hyponasality, nasal emission and nasal turbulence a three-point scale was used. Finally, the presence of nasal grimace was judged upon a two-point scale.

Articulation was evaluated using a picture-naming test. This test elicits 135 words using black and white drawings, resulting in a speech sample that includes all isolated consonants and most consonant clusters in all permissible positions in Dutch. All utterances were phonetically transcribed using the International Phonetic Alphabet (IPA), IPA extensions (Association, 1999) and symbols for cleft related speech disorders (Trost, 1981). Based on these transcriptions, a phonetic analysis was performed examining distortions, substitutions, additions, and omissions at phoneme level. For the phonological analysis at word level, Ingram's classification (Ingram, 1981) was used (syllable structure processes, substitution processes and assimilation processes). A phonological process was considered present when it occurred at least 4 times and the occurrence frequency was $20 \%$ or higher (McReynolds \& Elbert, 1981). 
Cleft related articulation disorders were evaluated separately, taking into account obligatory (e.g. weak production of plosives and fricatives) and compensatory disorders (e.g. glottal stops and pharyngeal fricatives). The occurrence frequency of phonetic and phonological processes and cleft-related articulation was calculated based on the number of potential occurrences (Luyten et al., 2013).

All speech samples were recorded using a Sony Handycam HDR-CQ280E with a built-in high quality microphone and collected in the home environment of the participants or in a clinical room of the Ghent University Hospital. Perceptual assessments were conducted by two speech and language pathologists (SLP's) (L.B., C.H.) with each one year experience in the evaluation of cleft palate speech. Speech samples were judged simultaneously but independently, as described by Shriberg, Kwiatkowski, and Hoffmann (1984). In case of disagreement, samples were replayed and discussed by the assessors until a consensus was reached. This consensus was used for further analysis. Before the actual assessments, a training session of approximately two hours was organized in order to ensure a comparable internal standard of the listeners. Training included a presentation of the speech parameters and their definitions as described by John et al. (2006), and consensus evaluation of external reference samples representing a range of severity. 


\subsection{Instrumental assessment of resonance}

Nasalance values were determined using the Kay Pentax Nasometer II (Model 6450). The Nasometer captures acoustic energy from both the oral and nasal cavity with microphones attached to a plate, which is placed between the mouth and nose of the patient. The nasalance value is the ratio of nasal acoustic energy and nasal plus oral acoustic energy, multiplied by 100. Prior to data collection, the Nasometer was calibrated following the guidelines described by the manufacturer. Nasalance values were calculated following the sustained phonation of the phonemes [a:], [i:], [u:] and [m], and repetition of the sentences of the SNAP test (Van Lierde et al., 2002) and the oronasal, oral and nasal text (Van de Weijer \& Slis, 1991). Phonemes and sentences were repeated respectively four and two times, after which a mean nasalance value was calculated. The texts were repeated only once. The oronasal text contains 11.67 $\%$ nasal consonants, approximately the same percentage as was found in standard Dutch speech (11.63\%) (Van den Broecke, 1988), and is comparable to the Rainbow passage in English (Fairbanks, 1960). In the oral text, which is comparable to the Zoo passage (Fletcher, 1978), no nasal consonants are present. In contrast, the nasal text contains $57 \%$ nasal consonants (Van Lierde, Wuyts, Bodt, \& Cauwenberge, 2001).

In addition, the Nasality Severity Index 2.0 (NSI 2.0) (Bettens, Van Lierde, Corthals, Luyten, \& Wuyts, 2015), a weighted measure of hypernasality, was determined. To do so, a sustained production of the vowel [i:] of minimum two seconds was recorded with a unidirectional condenser microphone (Samson 
C01U) using Praat-software, version 5.4 (Boersma \& Weenink). Based on this sample, the "voice low tone to high tone ratio" (VLHR) was determined. Subsequently, the NSI 2.0 was calculated with the NSI 2.0 script for Praat, using the VLHR and the edited nasalance values of [u:] and the oral text. A negative NSI 2.0 indicates the presence of hypernasality, whereas a positive NSI value indicates the absence of hypernasality.

\subsection{Statistical analysis}

Statistical analyses were performed using SPSS Statistics version 24.0 (SPSS Inc., Chicago, Illinois). The significance level $\alpha$ was set at $\leq 0.05$. For the analysis of categorical data, Fisher's exact test was used, as the expected cell counts of the cross tabulations did not meet the assumption of a Chi-Square test. For the analysis of continuous variables (nasalance values, NSI 2.0 and the occurrence frequency of phonetical and phonological processes and cleft-related articulation disorders) the Mann-Whitney $U$ test was performed as the distributions deviated from normal. There were missing values for the nasalance values of the sentences and the texts in the patient group. Therefore, if these values were missing, the nasalance values of the matched control participant were not considered in the analysis as well. Inter-rater reliability for the evaluation of speech intelligibility/distinctiveness, hypernasality, hyponasality, nasal emission, nasal turbulence and nasal grimace was calculated by means of intraclass correlation coefficients (ICC; single measures, two-way mixed, absolute agreement) and interpreted following the guidelines provided by 
Cicchetti and Sparrow (1981). For the assessment of articulation, a percentage of inter-rater agreement point-by-point was determined.

\section{Results}

3.1. Perceptual assessment of speech: intelligibility/distinctiveness, resonance, nasal airflow and nasal grimace

ICC's were excellent for all parameters: speech intelligibility/distinctiveness (0.965), hypernasality (0.916), nasal emission (0.800), nasal turbulence (0.890) and nasal grimace (1.000). As none of the participants presented with hyponasality, no ICC could be calculated for this parameter. In seven patients, speech intelligibility/distinctiveness was disordered (table 4). Also, twelve patients presented with mild to moderate hypernasality, and nasal emission and nasal turbulence were perceived in thirteen and five patients respectively. These perceptual evaluations were significantly worse in the patient group in comparison with the control group $(p<0.05)$.

\subsection{Perceptual assessment of speech: phonetic and phonological analysis}

The mean inter-rater reliability for the evaluation of articulation was $87.2 \%$ $(S D: 5.1 \%)$. Results of the phonetic analysis are displayed in table 2 , showing a significantly higher prevalence of consonant substitutions $(U=205.00, z=+2.90, p$ $=0.003, r=+0.51)$ and omissions $(\mathrm{U}=195.50, \mathrm{z}=+2.55, \mathrm{p}=0.010, \mathrm{r}=+0.45)$ in the speech of patients with cleft palate following Sommerlad's palatoplasty in 
Table 2: Results of the perceptual evaluation of speech intelligibility/distinctiveness, hypernasality, hyponasality, nasal turbulence, nasal emission and nasal grimace, and the results of Fisher's exact test.

\begin{tabular}{|c|c|c|c|}
\hline & $\begin{array}{c}\text { Patient group } \\
\quad(n=16)\end{array}$ & $\begin{array}{c}\text { Control } \\
\text { group } \\
(n=16)\end{array}$ & $p$ \\
\hline \multicolumn{4}{|l|}{ Speech intelligibility/distinctiveness } \\
\hline $\begin{array}{l}\text { 0: normal } \\
\text { 1: different, not enough to cause comment } \\
\text { 2: different enough to cause comment, but } \\
\text { intelligbile } \\
\text { 3: just intelligible to strangers } \\
\text { 4: impossible to understand }\end{array}$ & $\begin{array}{l}1 \\
8 \\
5 \\
2 \\
0\end{array}$ & $\begin{array}{l}15 \\
1 \\
0 \\
0 \\
0\end{array}$ & $<0.001^{*}$ \\
\hline \multicolumn{4}{|l|}{ Hypernasality } \\
\hline $\begin{array}{l}\text { 0: absent } \\
\text { 1: borderline } \\
\text { 2: mild } \\
\text { 3: moderate } \\
\text { 4: severe }\end{array}$ & $\begin{array}{l}1 \\
3 \\
7 \\
5 \\
0\end{array}$ & $\begin{array}{l}14 \\
2 \\
0 \\
0 \\
0\end{array}$ & $<0.001^{*}$ \\
\hline \multicolumn{4}{|l|}{ Hyponasality } \\
\hline $\begin{array}{l}0: \text { absent } \\
\text { 1: mild } \\
\text { 2: marked }\end{array}$ & $\begin{array}{l}16 \\
0 \\
0\end{array}$ & $\begin{array}{l}16 \\
0 \\
0\end{array}$ & N.A. \\
\hline \multicolumn{4}{|l|}{ Nasal emission } \\
\hline $\begin{array}{l}\text { 0: absent } \\
\text { 1: occasionally heard } \\
\text { 2: frequently heard }\end{array}$ & $\begin{array}{l}3 \\
8 \\
5\end{array}$ & $\begin{array}{l}16 \\
0 \\
0\end{array}$ & $<0.001^{*}$ \\
\hline \multicolumn{4}{|l|}{ Nasal turbulence } \\
\hline 0 : absent & 11 & 16 & $0.043^{*}$ \\
\hline
\end{tabular}




\begin{tabular}{|l|l|l|l|}
\hline $\begin{array}{l}\text { 1: occasionally heard } \\
\text { 2: frequently heard }\end{array}$ & 4 & 0 & \\
\hline Nasal grimace & 1 & 0 & \\
\hline $0:$ absent & 14 & 16 & 0.484 \\
1: grimace behavior & 2 & 0 & \\
\hline
\end{tabular}

* Statistically significant, $\mathrm{p} \leq 0.05$ 
Table 3: descriptive statistics (median, quartiles, range) of the occurrence frequency of phonetical processes in the experimental group and the control group, and the results of the Mann-Whitney $U$ test

\begin{tabular}{|c|c|c|c|c|c|c|c|c|c|c|c|}
\hline & \multicolumn{4}{|c|}{ Patient group $(n=16)$} & \multicolumn{4}{|c|}{ Control group $(n=16)$} & \multirow[t]{2}{*}{$\boldsymbol{U}$} & \multirow[t]{2}{*}{$p$} & \multirow[t]{2}{*}{$r$} \\
\hline & Median & Q1 & Q3 & Range & Median & Q1 & $\mathbf{Q 3}$ & Range & & & \\
\hline Consonant omission & 2.51 & 0.98 & 10.78 & $0.00-8.57$ & 0.61 & 0.06 & 1.79 & $0.00-8.31$ & 195.50 & $0.010 *$ & +0.45 \\
\hline Consonant addition & 0.50 & 0.00 & 1.21 & $0.00-2.33$ & 0.12 & 0.00 & 0.49 & $0.00-1.22$ & 178.00 & 0.061 & +0.34 \\
\hline Consonant substitution & 37.89 & 2.59 & 15.70 & $3.91-2.27$ & 27.38 & 0.80 & 3.94 & $0.00-2.36$ & 205.00 & $0.003 *$ & +0.51 \\
\hline Consonant distortion & 6.16 & 19.00 & 46.94 & 0.7327 .87 & 1.86 & 11.19 & 33.66 & $0.00-8.80$ & 178.00 & 0.061 & +0.33 \\
\hline
\end{tabular}

* Statistically significant, $\mathrm{p} \leq 0.05$ 
Table 4: descriptive statistics (median, quartiles, range) of the occurrence frequency of phonological processes in the experimental group and the control group, and the results of the Mann-Whitney $U$ test

\begin{tabular}{|c|c|c|c|c|c|c|c|c|c|c|c|}
\hline & \multicolumn{4}{|c|}{ Patient group $(n=16)$} & \multicolumn{4}{|c|}{ Control group $(n=16)$} & \multirow[t]{2}{*}{$U$} & \multirow[t]{2}{*}{$p$} & \multirow[t]{2}{*}{$r$} \\
\hline & Median & Q1 & Q3 & Range & Median & Q1 & Q3 & Range & & & \\
\hline $\begin{array}{l}\text { Syllable structure } \\
\text { processes }\end{array}$ & & & & & & & & & & & \\
\hline Deletion final consonants & 3.33 & 0.42 & 11.82 & $\begin{array}{l}0.00- \\
24.17\end{array}$ & 0.42 & 0.00 & 1.68 & $\begin{array}{l}0.00- \\
9.17\end{array}$ & 192.50 & $0.014 *$ & +0.44 \\
\hline Deletion initial consonants & 0.00 & 0.00 & 0.79 & $\begin{array}{r}0.00- \\
5.79\end{array}$ & 0.00 & 0.00 & 0.00 & $\begin{array}{r}0.00- \\
1.63\end{array}$ & 160.50 & 0.224 & +0.32 \\
\hline $\begin{array}{l}\text { Cluster simplification: } \\
\text { cluster reduction }\end{array}$ & 6.19 & 2.53 & 23.91 & $\begin{array}{l}0.00- \\
62.03\end{array}$ & 1.82 & 0.30 & 4.86 & $\begin{array}{l}0.00- \\
36.14\end{array}$ & 190.00 & $0.019 *$ & +0.41 \\
\hline $\begin{array}{l}\text { Cluster simplification: } \\
\text { epenthesis }\end{array}$ & 1.23 & 0.00 & 5.02 & $\begin{array}{l}0.00- \\
12.05\end{array}$ & 0.60 & 0.00 & 2.12 & $\begin{array}{r}0.00- \\
6.02\end{array}$ & 152.00 & 0.381 & +0.17 \\
\hline Coalescence syllables & 0.00 & 0.00 & 1.93 & $\begin{array}{r}0.00- \\
3.37\end{array}$ & 0.00 & 0.00 & 1.10 & $\begin{array}{r}0.00- \\
1.12\end{array}$ & 148.50 & 0.445 & +0.16 \\
\hline Coalescence sounds & 0.00 & 0.00 & 0.00 & $0.00-$ & 0.00 & 0.00 & 0.00 & $0.00-$ & 112.50 & 0.564 & -0.18 \\
\hline
\end{tabular}




\begin{tabular}{|c|c|c|c|c|c|c|c|c|c|c|c|}
\hline & & & & 0.73 & & & & 1.39 & & & \\
\hline \multicolumn{12}{|c|}{ Substitution processes } \\
\hline Fronting & 1.72 & 0.00 & 3.54 & $\begin{array}{l}0.00- \\
10.17\end{array}$ & 0.00 & 0.00 & 1.70 & $\begin{array}{r}0.00- \\
5.08\end{array}$ & 182.00 & $0.043^{*}$ & +0.40 \\
\hline Backing & 4.88 & 1.11 & 16.69 & $\begin{array}{l}0.00- \\
30.80\end{array}$ & 0.00 & 0.00 & 0.00 & $\begin{array}{r}0.00- \\
3.13\end{array}$ & 222.50 & $<0.001 *$ & +0.67 \\
\hline Stopping & 1.91 & 0.00 & 4.64 & $\begin{array}{l}0.00- \\
11.65\end{array}$ & 0.00 & 0.00 & 0.95 & $\begin{array}{r}0.00- \\
3.81\end{array}$ & 184.50 & $0.032 *$ & +0.40 \\
\hline Liquid gliding & 0.00 & 0.00 & 2.09 & $\begin{array}{l}0.00- \\
21.21\end{array}$ & 0.00 & 0.00 & 1.01 & $\begin{array}{l}0.00- \\
22.22\end{array}$ & 148.50 & 0.445 & +0.16 \\
\hline Denasalization & 0.00 & 0.00 & 0.00 & $\begin{array}{r}0.00- \\
1.69\end{array}$ & 0.00 & 0.00 & 0.00 & $\begin{array}{r}0.00- \\
0.00\end{array}$ & 152.00 & 0.381 & +0.32 \\
\hline Devoicing & 15.80 & 6.28 & 39.06 & $\begin{array}{l}2.08- \\
66.67\end{array}$ & 8.33 & 4.19 & 20.83 & $\begin{array}{l}0.00- \\
42.55\end{array}$ & 163.00 & 0.196 & +0.23 \\
\hline \multicolumn{12}{|c|}{ Assimilation processes } \\
\hline Assimilation & 0.00 & 0.00 & 0.74 & $\begin{array}{r}0.00- \\
0.76\end{array}$ & 0.00 & 0.00 & 0.75 & $\begin{array}{r}0.00- \\
2.96\end{array}$ & 122.50 & 0.838 & -0.04 \\
\hline Reduplication & 0.00 & 0.00 & 0.56 & $0.00-$ & 0.00 & 0.00 & 0.00 & $0.00-$ & 134.00 & 0.838 & +0.05 \\
\hline
\end{tabular}




\begin{tabular}{|c|c|c|c|c|c|c|c|c|c|c|c|}
\hline & & & & 3.08 & & & & 4.76 & & & \\
\hline Metathesis & 0.00 & 0.00 & 0.00 & $\begin{array}{r}0.00- \\
0.00\end{array}$ & 0.00 & 0.00 & 0.00 & $\begin{array}{r}0.00- \\
2.26\end{array}$ & 120.00 & 0.780 & -0.18 \\
\hline Substitution $n->m$ & 0.00 & 0.00 & 4.30 & $\begin{array}{r}0.00- \\
7.69\end{array}$ & 0.00 & 0.00 & 0.00 & $\begin{array}{r}0.00- \\
2.63\end{array}$ & 157.00 & 0.287 & +0.24 \\
\hline
\end{tabular}

* Statistically significant, $\mathrm{p} \leq 0.05$ 
comparison to the control group. The phonological analysis showed differences between these groups as well (table 3 ). The phonological processes 'deletion of the final consonant' $(U=192.50, z=+2.50, p=0.014, r=+0.44)$, 'cluster simplification by cluster reduction' $(U=190.00, z=+2.35, p=0.019, r=+0.41)$, 'fronting' $(U=182.00, z=+2.21, p=0.043, r=+0.40)$, 'backing' $(U=222.50, z=+3.81, p$ $<0.001, r=+0.67)$ and 'stopping' $(U=184.50, z=+2.28, p=0.032, r=+0.40)$ were significantly more present in the speech of the patient group. In nine patients at least one phonological process was present, whereas this was the case in six participants of the control group. However, this number was not significantly

different between both groups $(U=163.00, z=+1.45, p=0.196, r=+0.26)$. The median percentage of occurrence of obligatory and compensatory articulation disorders in the speech of patients with cleft palate was 8.94\% (Q1-Q3: 3.34 13.60, range: $0.00 \%$ to $32.73 \%)$ and $0.43 \%(\mathrm{Q} 1-\mathrm{Q} 3: 0.00-5.22$, range: 0.00 to 37.72) respectively.

\subsection{Instrumental assessment of resonance: nasometry and NSI 2.0}

Results of the instrumental assessment of resonance are presented in table 5. All median nasalance values differed significantly between the patient group and the control group with the exception of nasalance values of nasal speech material. As such, no significant differences were found between groups for the phoneme $[\mathrm{m}](U=79.50, z=-1.84, p=0.067, r=-0.32)$, nasal sentences $(U=$ $16.50, z=-1.03, p=0.318, r=-0.28)$ and the nasal text $(U=53.00, z=+1.11$, $p=0.297, r=+0.26)$. A median NSI value of -1.75 was found in the patient group, whereas in the control group a positive median NSI value of +4.03 was 
Table 5: descriptive statistics (median, quartiles and range) of nasalance values at phoneme, sentence and text level in the experimental group and the control group and the results of the Mann-Whitney $U$ test

\begin{tabular}{|c|c|c|c|c|c|c|c|c|c|c|c|}
\hline & \multicolumn{4}{|c|}{ Patient group } & \multicolumn{4}{|c|}{ Control group } & \multirow[t]{2}{*}{$U$} & \multirow[t]{2}{*}{$p$} & \multirow[t]{2}{*}{$r$} \\
\hline & Median & Q1 & Q3 & Range & Median & Q1 & Q3 & Range & & & \\
\hline $\begin{array}{l}\text { Nasometry: } \\
\text { sounds }\end{array}$ & \multicolumn{4}{|c|}{$n=16$} & \multicolumn{4}{|c|}{$n=16$} & & & \\
\hline [a:] & 16.50 & 13.25 & 21.75 & $6-34$ & 7.00 & 6.00 & 11.75 & $5-47$ & 216.00 & $0.001 *$ & +0.59 \\
\hline [i:] & 48.50 & 20.75 & 57.00 & $14-68$ & 26.00 & 16.75 & 28.75 & $9-41$ & 193.00 & $0.014^{*}$ & +0.43 \\
\hline [u:] & 36.00 & 14.50 & 47.00 & $8-50$ & 11.00 & 8.25 & 13.50 & $6-36$ & 212.00 & $0.001 *$ & +0.56 \\
\hline [m] & 88.00 & 83.75 & 91.50 & $74-94$ & 90.00 & 88 & 93.75 & $84-95$ & 79.50 & 0.067 & -0.32 \\
\hline $\begin{array}{l}\text { Nasometry: } \\
\text { sentences }\end{array}$ & \multicolumn{4}{|c|}{$n=7$} & \multicolumn{4}{|c|}{$n=7$} & & & \\
\hline Bilabial & 21.00 & 12.00 & 24.00 & $8-32$ & 12.00 & 10.00 & 12.00 & $5-12$ & 41.00 & $0.038^{*}$ & +0.58 \\
\hline Alveolar & 23.00 & 18.00 & 28.00 & $12-32$ & 10.00 & 8.00 & 19.00 & $7-21$ & 44.00 & $0.011^{*}$ & +0.67 \\
\hline Velar & 25.00 & 23.00 & 32.00 & $14-40$ & 21.00 & 18.00 & 22.00 & $12-26$ & 40.00 & 0.053 & +0.53 \\
\hline Sibilants & 25.00 & 20.00 & 37.00 & $11-38$ & 15.00 & 8.00 & 19.00 & $8-22$ & 43.00 & $0.017^{*}$ & +0.63 \\
\hline Nasal & 45.00 & 45.00 & 51.00 & $37-54$ & 48.00 & 46.00 & 50.00 & $38-59$ & 16.50 & 0.318 & -0.28 \\
\hline Nasometry: texts & \multicolumn{4}{|c|}{$n=15$} & \multicolumn{4}{|c|}{$n=15$} & & & \\
\hline
\end{tabular}




\begin{tabular}{|c|c|c|c|c|c|c|c|c|c|c|c|}
\hline Oronasal text & 36.00 & 29.00 & 40.00 & $21-48$ & 26.00 & 22.00 & 29.00 & $20-37$ & 193.00 & $\begin{array}{r}< \\
0.001^{*}\end{array}$ & +0.61 \\
\hline Oral text & \multicolumn{4}{|c|}{$n=9$} & \multicolumn{4}{|c|}{$n=9$} & & & \\
\hline \multirow[t]{2}{*}{ Nasal text } & 50.00 & 47.50 & 53.00 & $45-66$ & 48.00 & 41.00 & 52.00 & $36-53$ & 53.00 & 0.297 & +0.26 \\
\hline & \multicolumn{4}{|c|}{$n=13$} & \multicolumn{4}{|c|}{$n=13$} & & & \\
\hline NSI 2.0 & -1.75 & -6.23 & +2.07 & $\begin{array}{r}(-9.09)- \\
(+5.64)\end{array}$ & +4.03 & +1.58 & +4.95 & $\begin{array}{r}(-1.87)- \\
(+5.12)\end{array}$ & 35.00 & $0.010^{*}$ & -0.50 \\
\hline
\end{tabular}

* Statistically significant, $\mathrm{p} \leq 0.05$ 
found. This difference in median NSI values between groups was statistically significant $(U=35.00, z=-2.54, p=0.010, r=-0.50)$.

\section{Discussion}

This study provides detailed speech outcomes following Sommerlad's primary palatoplasty as performed by a single surgeon of the Ghent University Hospital. In general, a significant difference was found for all speech parameters (speech intelligibility/distinctiveness, resonance, nasal airflow and articulation) between the patient group and the control group.

Nine patients of the study group presented with intelligible and acceptable speech at a mean age of 5.4 years old, being similar with intelligibility ratings reported by Andrades et al. (2008) and Doucet et al. (2013), who described intelligible speech in 19 of 30 patients, and 15 of 20 patients respectively. In addition to the results described by the latter authors, our study is one of the few describing speech intelligibility and distinctiveness in patients following Sommerlad's palatoplasty. Using this assessment parameter, a global insight in the speech performance of these patients was obtained (John et al., 2006), as intelligible and acceptable speech contributes to the well-functioning of the patient in society.

None of the patients presented with severe hypernasality, which was in alignment with the results of previous studies (Andrades et al., 2008; Doucet et 
al., 2013; Luyten et al., 2014; Luyten et al., 2013; Sommerlad et al., 2004). Also, four of our sixteen patients were perceived as having normal resonance. This ratio of patients without hypernasality was similar to those reported by Sommerlad et al. (2004) and Andrades et al. (2008). However, it should be noted that the results reported by Sommerlad et al. (2004) were those of a patient group with a submucosal cleft palate and that no specific information regarding cleft type of the patient group was provided by Andrades et al. (2008). In addition, nasal emission and nasal turbulence were present in thirteen and five patients respectively. Thus, even following Sommerlad's palatoplasty a relatively high occurrence frequency of resonance and nasal airflow disorders was found, suggesting insufficient velopharyngeal closure in these patients. However, the lack of instrumental assessment of the velopharyngeal function (e.g. nasoendoscopy or videofluoroscopy) is one of the main limitations of this study and hence, no conclusions can be drawn regarding the prevalence of velopharyngeal insufficiency.

The assessment of articulation disorders included a phonetic and phonological analysis, and the evaluation of cleft related articulation disorders, as was common practice at the Ghent University Hospital. This approach made the comparison of speech results between groups possible. On the other hand, the assessment of speech intelligibility/distinctiveness, resonance and nasal airflow was conducted using the EAI scales of the CAPS-A protocol (John et al., 2006). Although the validity and reliability of this English instrument were tested rigorously (Britton et al., 2014; John et al., 2006; Pereira, Sell, \& 
Tuomainen, 2013; Sell et al., 2009), we acknowledge the need for a Dutch framework for the assessment of speech in patients with cleft palate. This framework should be in alignment with internationally acknowledged guidelines, in order to obtain standardization (Lohmander, Borell, Henningsson, Havstam, \& Persson, 2005). As such, this would allow for within-center and inter-center comparisons (Shaw et al., 2005). Comparison of the results of the phonetic and phonological analysis was only possible with the studies by Luyten et al. (2014); Luyten et al. (2013) as in those studies a similar approach was used. In line with the findings by Luyten et al. (2013) more omissions and substitutions were present in the patient group than in the control group. On the other hand, more patients with at least one present phonological process were found by Luyten et al. (2014); Luyten et al. (2013) than in this study. As the patient groups had a similar age at the moment of the assessment, this difference might be explained by the internal standard the assessors applied when performing the phonetic and phonological analysis (Sell, 2005).

Perceptual evaluations were performed by two SLP's with rather limited, i.e. one year, experience in cleft palate speech. Chapman et al. (2016) described listener characteristics, such as experience, as important influencing variables of the reliability of perceptual assessments. While in several studies better reliability was found in experienced listeners compared to inexperienced listeners (Gooch, Hardin-Jones, Chapman, Trost-Cardamone, \& Sussman, 2001; Keuning, Wieneke, \& Dejonckere, 1999; Lewis, Watterson, \& Houghton, 2003), other studies did not (Brunnegård, Lohmander, \& van Doorn, 2009; Tönz et al., 
2002). Based on the interpretation of the ICC's and the mean percentage of agreement for the assessment of articulation, the inter-rater reliability of the evaluations performed in this study can be considered excellent (Cicchetti \& Sparrow, 1981). The training conducted before the actual analyses, using consensus listening of external reference samples, might have played an important role in these excellent results (Sell et al., 2009). Nevertheless, we do acknowledge that assessments performed by assessors with rather limited experience in the specific features of cleft palate speech is not ideal for outcome studies. Therefore, objective assessments of speech, using nasometry and the NSI 2.0 are of added value when interpreting our results. These objective measurements confirmed the results of the perceptual evaluations, with the median nasalance and NSI 2.0 values indicating the presence of hypernasality in the patient group.

A major limitation of this study, is the small sample size of a heterogeneous group (e.g. cleft type and age at the time of the assessment). Moreover, audiological and dental or orthodontic findings are missing. To avoid these limitations in future studies, routine follow-up at well-defined ages should be performed including speech assessment, instrumental assessment of velopharyngeal function, audiological assessment and dental examination. As a result, this routine outcome assessment will allow for a more standardized follow-up and referral of these patients for further treatment. For the current study, no comparison group with cleft palate following a different technique for palatal closure was included, as the focus was to report outcomes of 
Sommerlad's technique performed by a single surgeon of the Ghent University Hospital. As this study was the first to report the outcomes of this craniofacial center, the detailed description of speech outcomes is of clinical importance and has laid the basis for further research. In the future, a Dutch speech assessment protocol will be developed to allow for within-center and inter-center outcome comparisons.

\section{Conclusion}

Several patients still presented with both obligatory and compensatory speech disorders following Sommerlad's primary palatoplasty, with significantly worse speech results in comparison to a control group without cleft palate. This study lays the basis for further outcome studies at the Ghent University Hospital. As a rigorous interpretation of our findings against previously described results was hindered by the lack of standardization in the assessment of speech in patients with cleft palate, a validated Dutch speech assessment protocol to allow for within-center and inter-center comparisons will be developed by our research group.

\section{Acknowledgments}

Research funded by a PhD grant of the Research Foundation Flanders (FWO). None of the authors has a financial interest in any of the products, devices, or 
drugs mentioned in this manuscript. The authors would like to thank C.H. for her contribution to the data collection.

\section{$\underline{\text { References }}$}

Agrawal, K. (2009). Cleft palate repair and variations. Indian Journal of Plastic Surgery, 42(3), 102.

Andrades, P., Espinosa-de-los-Monteros, A., Shell, D. H. t., Thurston, T. E., Fowler, J. S., Xavier, S. T., . . . Grant, J. H., 3rd. (2008). The importance of radical intravelar veloplasty during two-flap palatoplasty. Plastic and reconstructive surgery, 122(4), 1121-1130. doi:10.1097/PRS.0b013e3181845a21

Association, I. P. (1999). Handbook of the International Phonetic Association: A guide to the use of the International Phonetic Alphabet: Cambridge University Press.

Bardach, J. (1995). Two-flap palatoplasty: Bardach's technique. Operative techniques in plastic and reconstructive surgery, 2(4), 211-214.

Bettens, K., Van Lierde, K. M., Corthals, P., Luyten, A., \& Wuyts, F. L. (2015). The Nasality Severity Index 2.0: revision of an objective multiparametric approach to hypernasality. The Cleft palate-craniofacial journal.

Boersma, W., \& Weenink, D. PRAAT: doing phonetics by computer (Version 5.4.).

Borel-Maisonny, S. (1975). L'insuffisance vélaire, point de vue de l'orthophoniste. Reeduc Orthophon, 13, 61-81.

Britton, L., Albery, L., Bowden, M., Harding-Bell, A., Phippen, G., \& Sell, D. (2014). A CrossSectional Cohort Study of Speech in Five-Year-Olds With Cleft Palate \pm Lip to Support 
Development of National Audit Standards: Benchmarking Speech Standards in the United Kingdom. The Cleft palate-craniofacial journal, 51(4), 431-451.

Brunnegård, K., Lohmander, A., \& van Doorn, J. (2009). Untrained listeners' ratings of speech disorders in a group with cleft palate: a comparison with speech and language pathologists ,ratings. International Journal of Language \& Communication Disorders, 44(5), 656-674.

Chapman, K. L., Baylis, A., Trost-Cardamone, J., Cordero, K. N., Dixon, A., Dobbelsteyn, C., . . . Sell, D. (2016). The Americleft Speech Project: A Training and Reliability Study. The Cleft palate-craniofacial journal, 53(1), 93-108. doi:10.1597/14-027

Cicchetti, D. V., \& Sparrow, S. A. (1981). Developing criteria for establishing interrater reliability of specific items: applications to assessment of adaptive behavior. American journal of mental deficiency.

Dissaux, C., Grollemund, B., Bodin, F., Picard, A., Vazquez, M.-P., Morand, B., ... . BruantRodier, C. (2016). Evaluation of 5-year-old children with complete cleft lip and palate: Multicenter study. Part 2: Functional results. Journal of Cranio-Maxillofacial Surgery, 44(2), 94-103.

Dixon, M. J., Marazita, M. L., Beaty, T. H., \& Murray, J. C. (2011). Cleft lip and palate: understanding genetic and environmental influences. Nature Reviews Genetics, 12(3), 167-178.

Doucet, J. C., Herlin, C., Captier, G., Baylon, H., Verdeil, M., \& Bigorre, M. (2013). Speech outcomes of early palatal repair with or without intravelar veloplasty in children with complete unilateral cleft lip and palate. Br J Oral Maxillofac Surg, 51(8), 845-850. doi:10.1016/j.bjoms.2013.04.016

Fairbanks, G. (1960). Voice and Articulation Drillbook. 1960: New York: Harper \& Row. 
Fisher, D. M. (2005). Unilateral cleft lip repair: an anatomical subunit approximation technique. Plastic and reconstructive surgery, 116(1), 61-71.

Fletcher, S. G. (1978). Diagnosing speech disorders from cleft palate: Saunders.

Gooch, J. L., Hardin-Jones, M., Chapman, K. L., Trost-Cardamone, J. E., \& Sussman, J. (2001). Reliability of listener transcriptions of compensatory articulations. The Cleft palatecraniofacial journal, 38(1), 59-67.

Harding, A., \& Grunwell, P. (1996). Characteristics of cleft palate speech. International Journal of Language \& Communication Disorders, 31(4), 331-357. doi:10.3109/13682829609031326

Harding, A., Harland, K., \& Razzell, R. (1997). Cleft audit protocol for speech (CAPS). Broomfield, Chelmsford, Essex: St. Andrew's Plastic Surgery Centre.

Henningsson, G., Kuehn, D. P., Sell, D., Sweeney, T., Trost-Cardamone, J. E., \& Whitehill, T. L. (2008). Universal parameters for reporting speech outcomes in individuals with cleft palate. The Cleft palate-craniofacial journal, 45(1), 1-17.

Ingram, D. (1981). Procedures for the phonological analysis of children's language (Vol. 2): University Park Press.

John, A., Sell, D., Sweeney, T., Harding-Bell, A., \& Williams, A. (2006). The cleft audit protocol for speech-augmented: a validated and reliable measure for auditing cleft speech. The Cleft palate-craniofacial journal, 43(3), 272-288.

Keuning, K. H., Wieneke, G. H., \& Dejonckere, P. H. (1999). The intrajudge reliability of the perceptual rating of cleft palate speech before and after pharyngeal flap surgery: the effect of judges and speech samples. The Cleft palate-craniofacial journal, 36(4), 328-333.

Kummer, A. W. (2008). Cleft Palate \& Craniofacial Anomalies, Effects on Speech and Resonance.. San Diego, CA: Singular. Retrieved from 
Kummer, A. W. (2011). Speech therapy for errors secondary to cleft palate and velopharyngeal dysfunction. Paper presented at the Seminars in speech and language.

Leow, A.-M., \& Lo, L.-J. (2008). Palatoplasty: evolution and controversies. Chang Gung Medical Journal, 31(4), 335-345.

Lewis, K. E., Watterson, T. L., \& Houghton, S. M. (2003). The influence of listener experience and academic training on ratings of nasality. Journal of Communication Disorders, 36(1), 49-58.

Lohmander, A., Borell, E., Henningsson, G., Havstam, C., \& Persson, C. (2005). SVANTESVenskt Artikulations och Nasalitets TEst. Manual. Pedagogisk Design.

Luyten, A., Bettens, K., D'Haeseleer, E., De Ley, S., Hodges, A., Galiwango, G., . . V Van Lierde, K. (2014). The impact of palatal repair before and after 6 months of age on speech characteristics. International Journal of Pediatric Otorhinolaryngology, 78(5), 787-798. doi:10.1016/j.jporl.2014.02.012

Luyten, A., Bettens, K., D'Haeseleer, E., De Ley, S., Hodges, A., Galiwango, G., . . Van Lierde, K. (2013). Impact of early synchronous lip and palatal repair on speech. Folia Phoniatrica et Logopaedica, 65(6), 303-311. doi:10.1159/000362501

MacKay, I., \& Kummer, A. (1994). Simplified nasometric assessment procedures. Lincoln Park, NJ: Kay Elemetrics.

McReynolds, L. V., \& Elbert, M. (1981). Criteria for phonological process analysis. Journal of Speech and Hearing Disorders, 46(2), 197-204.

Moore, M. D., Lawrence, W. T., Ptak, J. J., \& Trier, W. C. (1988). Complications of primary palatoplasty: a twenty-one-year review. Surgery, 103, 53. 
Nyberg, J., Neovius, E., \& Lohmander, A. (2017). Speech outcomes at 5 and 10 years of age after one-stage palatal repair with muscle reconstruction in children born with isolated cleft palate. Journal of Plastic Surgery and Hand Surgery, 1-10.

Pereira, V. J., Sell, D., \& Tuomainen, J. (2013). Effect of maxillary osteotomy on speech in cleft lip and palate: perceptual outcomes of velopharyngeal function. International Journal of Language and Communication Disorders, 48(6), 640-650. doi:10.1111/1460-6984.12036

Rineau, G. (1993). L'aerophonoscope. Observation des déperditions nasales dans les divisions palatines au moyen de l'aerophonoscope [Evaluation of nasal emissions in the cleft palate patient with the aerophonoscope]. Revue Glossa, 34, 4.

Rudnick, E. F., \& Sie, K. C. (2008). Velopharyngeal insufficiency: current concepts in diagnosis and management. Current opinion in otolaryngology \& head and neck surgery, 16(6), 530-535.

Salyer, K. E., Sng, K. W., \& Sperry, E. E. (2006). Two-flap palatoplasty: 20-year experience and evolution of surgical technique. Plastic and reconstructive surgery, 118(1), 193-204.

Sell, D. (2005). Issues in perceptual speech analysis in cleft palate and related disorders: a review. International Journal of Language \& Communication Disorders, 40(2), 103-121. doi:10.1080/13682820400016522

Sell, D., Harding, A., \& Grunwell, P. (1999). GOS. SP. ASS.'98: an assessment for speech disorders associated with cleft palate and/or velopharyngeal dysfunction (revised). International Journal of Language \& Communication Disorders, 34(1), 17-33.

Sell, D., John, A., Harding-Bell, A., Sweeney, T., Hegarty, F., \& Freeman, J. (2009). Cleft audit protocol for speech (CAPS-A): a comprehensive training package for speech analysis. International Journal of Language and Communication Disorders, 44(4), 529-548. doi:10.1080/13682820802196815 
Shaw, W. C., Brattström, V., Mølsted, K., Prahl-Andersen, B., Roberts, C. T., \& Semb, G. (2005). The Eurocleft study: intercenter study of treatment outcome in patients with complete cleft lip and palate. Part 5: discussion and conclusions. The Cleft palatecraniofacial journal, 42(1), 93-98.

Shriberg, L. D., Kwiatkowski, J., \& Hoffmann, K. (1984). A procedure for phonetic transcription by consensus. Journal of Speech, Language, and Hearing Research, 27(3), 456-465.

Sie, K., \& Chen, E. Y. (2007). Management of velopharyngeal insufficiency: development of a protocol and modifications of sphincter pharyngoplasty. Facial plastic surgery: FPS, 23(2), 128-139.

Sommerlad. (2003). A technique for cleft palate repair. Plastic and reconstructive surgery, 112(6), 1542-1548. doi:10.1097/01.prs.0000085599.84458.d2

Sommerlad, B. C. (2002). The management of cleft lip and palate. Current Paediatrics, 12(1), 43-50.

Sommerlad, B. C., Fenn, C., Harland, K., Sell, D., Birch, M. J., Dave, R., . . Barnett, A. (2004). Submucous cleft palate: A grading system and review of 40 consecutive submucous cleft palate repairs. Cleft Palate-Craniofacial Journal, 41(2), 114-123. doi:10.1597/02-102

Talmant, J.-C., Talmant, J.-C., \& Lumineau, J.-P. (2007). Une approche fonctionnelle lors du traitement primaire des fentes labioalvéolopalatovélaires pour le minimum de séquelles. Revue de Stomatologie et de Chirurgie Maxillo-faciale, 108(4), 255-263.

Talmant, J. (2000). Current trends in the treatment of bilateral cleft lip and palate. ORAL AND MAXILLOFACIAL SURGERY CLINICS OF NORTH AMERICA, 12(3), 421-442.

Tönz, M., Schmid, I., Graf, M., Mischler-Heeb, R., Weissen, J., \& Kaiser, G. (2002). Blinded speech evaluation following pharyngeal flap surgery by speech pathologists and lay people in children with cleft palate. Folia Phoniatrica et Logopaedica, 54(6), 288-295. 
Trost, J. E. (1981). Articulatory additions to the classical description of the speech of persons with cleft palate. Cleft Palate J, 18(3), 193-203.

Van Borsel, J. (2003). Kinderen met spraakproductieproblemen. Leuven: Acco.

Van de Weijer, J., \& Slis, I. (1991). Nasaliteitsmeting met de nasometer. Logopedie en Foniatrie, 63, 97-101.

Van den Broecke, M. (1988). Frequenties van letters, lettergrepen, woorden en fonemen in het Nederlands. Ter sprake: spraak als betekenisvol geluid in, 36.

Van Lierde, K., De Bodt, M., Van Borsel, J., Wuyts, F., \& Van Cauwenberge, P. (2002). Effect of cleft type on overall speech intelligibility and resonance. Folia Phoniatrica et Logopaedica, 54(3), 158-168.

Van Lierde, K., Wuyts, F., Bodt, M. D., \& Cauwenberge, P. V. (2001). Nasometric values for normal nasal resonance in the speech of young Flemish adults. The Cleft palatecraniofacial journal, 38(2), 112-118.

Yang, Y., Li, Y., Wu, Y., Gu, Y., Yin, H., Long, H., . . . Zheng, Q. (2013). Velopharyngeal function of patients with cleft palate after primary palatoplasty: relevance of sex, age, and cleft type. Journal of Craniofacial Surgery, 24(3), 923-928. doi:10.1097/SCS.0b013e3182587b34 